\title{
Seryl-tRNA Synthetases in Translation and Beyond
}

\author{
Marko Močibob, Jasmina Rokov-Plavec, Vlatka Godinić-Mikulčić, Ita Gruić-Sovulj*
}

\author{
Department of Chemistry, Faculty of Science, University of Zagreb, Horvatovac 102a, HR-10000 Zagreb, Croatia \\ * Corresponding author's e-mail address: gruic@chem.pmf.hr \\ RECEIVED: May 18, 2016 * REVISED: July 29, 2016 * ACCEPTED: September 21, 2016
}

\begin{abstract}
For a long time seryl-tRNA synthetases (SerRSs) stood as an archetypal, canonical aminoacyl-tRNA synthetases (aaRS), exhibiting only basic tRNA aminoacylation activity and with no moonlighting functions beyond protein biosynthesis. The picture has changed substantially in recent years after the discovery that SerRSs play an important role in antibiotic production and resistance and act as a regulatory factor in vascular development, as well as after the discovery of mitochondrial morphogenesis factor homologous to SerRS in insects. In this review we summarize the recent research results from our laboratory, which advance the understanding of seryl-tRNA synthetases and further paint the dynamic picture of unexpected SerRS activities. SerRS from archaeon Methanothermobacter thermautotrophicus was shown to interact with the large ribosomal subunit and it was postulated to contribute to a more efficient translation by the"tRNA channeling" hypothesis. Discovery of the atypical SerRS in a small number of methanogenic archaea led to the discovery of a new family of enzymes in numerous bacteria - amino acid:[carrier protein] ligases (aa:CP ligases). These SerRS homologues resigned tRNA aminoacylation activity, and instead adopted carrier proteins as the acceptors of activated amino acids. The crystal structure of the aa:CP ligase complex with the carrier protein revealed that the interactions between two macromolecules are incomparable to tRNA binding by the aaRS and consequently represent a true evolutionary invention. Kinetic investigations of SerRSs and the accuracy of amino acid selection revealed that SerRSs possess pre-transfer proofreading activity, challenging the widely accepted presumption that hydrolytic proofreading activity must reside in an additional, separate editing domain, not present in SerRSs. Finally, the plant tRNA serylation system is discussed, which is particularly interesting due to the fact that protein biosynthesis takes place in three cellular compartments: cytosol, mitochondria and chloroplasts. Plant cytosolic SerRSs showed broad tRNA ${ }^{\text {Ser }}$ specificity and flexibility, unlike SerRSs from other organisms. High fidelity of SerRS dually targeted to mitochondria and chloroplasts indicated its importance in plant organellar quality control.
\end{abstract}

Keywords: seryl-tRNA synthetase, editing, proofreading, protein complexes, amino acid:[carrier protein] ligase, carrier protein, ribosome, plant.

\section{INTRODUCTION}

A MINOACYL-tRNA synthetases (aaRSs) are well known and well characterized enzymes with the fundamental role in the translation of the genetic code. Even before the exact mechanism of ribosomal translation was revealed and before the adaptor hypothesis was proposed, ${ }^{[1]}$ it was known that some sort of "activating enzymes" were needed for in vitro incorporation of amino acids into newly synthesized polypeptides. ${ }^{[2-6]}$ The fundamental role of aminoacyltRNA synthetases in protein biosynthesis is to provide aminoacyl-tRNAs, synthesized in a two-step reaction (Scheme 1), which then serve as the activated precursors for the polypeptide synthesis during ribosomal translation of the mRNA. Furthermore, aaRSs are crucial for the accurate interpretation and faithful translation of the genetic information, because aaRSs pair the correct amino acid with the corresponding tRNA. [7]

$$
\begin{gathered}
\text { amino acid + ATP } \rightarrow \text { aminoacyl-AMP + PPi } \\
\text { aminoacyl-AMP + tRNA } \rightarrow \text { aminoacyl-tRNA + AMP } \\
\text { amino acid + ATP + tRNA } \rightarrow \text { aminoacyl-tRNA + AMP + PPi } \\
\text { Scheme } 1
\end{gathered}
$$

Broadly speaking, incorporation of each of the twenty standard amino acids into the proteins is dependent on the existence of the corresponding aaRS, specific for that particular amino acid. ${ }^{[7]}$

Beside the well-established canonical role in the ribosomal translation, many aaRSs are engaged in diverse cellular processes unrelated to protein biosynthesis. Such 
unconventional functions are exemplified by mammalian bifunctional GluProRS which acts in translational gene silencing as the part of the GAIT complex in the interferone$\gamma$-dependent inflammatory response. ${ }^{[8]}$ Human LysRS is recruited to the gene expression regulation, through interaction with microphthalmia-associated transcription factor (MITF) and synthesis of diadenosine tetraphosphate ( $\left.\mathrm{Ap}_{4} \mathrm{~A}\right)$ which acts as the second messenger and transcriptional activator of the MIFT-targeted genes. ${ }^{[9]}$ Mammalian TyrRS and TrpRS have extracellular cytokine activity and stimulate or suppress angiogenesis, respectively. ${ }^{[10,11]}$ Yeast AspRS ${ }^{[12]}$ and ThrRS ${ }^{[13]}$ from Escherichia coli bind their own mRNA and autoregulate their expression on the level of translation. Mitochondrial TyrRS of Neurospora crassa works as a splicing factor through an interaction with a conserved tRNA-like structural motif in the group I intron. ${ }^{[14]}$ Furthermore, the eukaryotic aaRS often assemble into multisynthetase complexes incorporating additional noncatalytic scaffolding proteins. The best characterized multisynthetase complexes are yeast GluRS:Arc1p:MetRS complex ${ }^{[15,16]}$ and multisynthetase complex from vertebrates containing nine tRNA-aminoacylation activities and three additional scaffold proteins. ${ }^{[11,17]}$ Noncanonical functions of the aaRSs beyond translation and the propensity to assemble into multisynthetase complexes are often linked to the accretion of additional noncatalytical domains during evolution. ${ }^{[18]}$ Involvement of the aaRSs in health and disease received broad research interest because many pathologies have been linked to the aaRSs mutations. ${ }^{[19,20]}$

\section{Two Evolutionary Distinct SerRS Types}

Seryl-tRNA synthetase (SerRS) was the first class II aaRS whose crystal structure has been solved, ${ }^{[21]}$ and provided the structural basis for the aaRS classification in two distinct classes, based on the conserved signature motifs ${ }^{[22]}$ and architecture of the catalytic domain. ${ }^{[23]}$ Successive structural investigations ${ }^{[24-26]}$ revealed many peculiarities of the tRNA serylation system. Seryl-tRNA synthetases are homodimeric enzymes. Each monomer is composed of the globular C-terminal catalytic domain and a distinctive $\mathrm{N}$-terminal domain, consisting of two long ( $60 \AA$ ) , solvent exposed antiparallel coiled-coils, comprised of about 90 residues (Figure 1A). The $\mathrm{N}$-terminal domain functions as a tRNA-binding

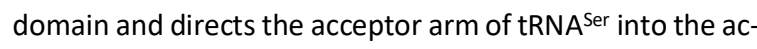
tive site of the catalytic domain in the opposite subunit. Hence, tRNA ${ }^{\text {ser }}$ binds across the both subunits (Figure $1 \mathrm{~A}$ ). Remarkably, the anticodon of the tRNA ${ }^{\text {Ser }}$ is solvent-exposed and not recognized as an identity element by the SerRS. ${ }^{[26]}$ Recent structural work on the SerRS system revealed new exciting findings: the crystal structure of bovine mitochondrial SerRS ${ }^{[27]}$ unveiled how the additional $\mathrm{N}$ - and C-terminal appendices compensate for the lost structural elements in deviant mitochondrial tRNA ${ }^{\text {Ser }}$ isoacceptors; and the crystal structure of Methanosarcina barkeri SerRS ${ }^{[28]}$ solved in our group exposed the unexpected idiosyncrasies of atypical SerRS from methanogenic archaea (Figure 1B). The first idiosyncratic feature of the atypical SerRS from methanogenic archaea is that the $\mathrm{N}$-terminal tRNA-binding domain has a completely different and unrelated fold compared to the conventional SerRS found in all three domains of life and exemplified by the bacterial counterparts (Figure 1A). While typical SerRSs possess the extended coiled-coil $\mathrm{N}$-terminal tRNA-binding domain, the $\mathrm{N}$ terminal domain of the atypical SerRS from $M$. barkeri is larger (approx. 170 residues) and it is composed of the six stranded $\beta$-sheet capped by 3 short $\alpha$-helices (Figure 1B). The catalytic domain has additional insertions proven to be functionally important ${ }^{[29,30]}$ but most remarkably, the architecture of the active site has changed: a zinc ion has been found in the active site and participates in serine binding. Thus, the atypical SerRS evolved a distinctive mechanism of substrate recognition. In the last few years the crystal structure of archaeal Pyrococcus horikoshii SerRS ${ }^{[31]}$ (homologous to conventional, bacterial-type enzyme) has been solved, eukaryotic SerRS from fungus Candida albicans ${ }^{[32]}$ and protozoa Trypanosoma brucei[33] have their structures deciphered and finally the structure of human SerRS was determined. [34] Nowadays, the complete repertoire of SerRS crystal structures is available, from all three domains of life, including lower and higher eukaryotes and different cellular compartments. The archaeal and eukaryotic SerRSs in general recapitulate the structure and characteristics of the bacterial enzymes except in the case of SerRSs from methanogenic archaea. Therefore, the majority of eukaryotic and archaeal SerRSs that structurally resemble the bacterial counterparts are called canonical or typical or bacterial-type SerRSs, whereas the SerRSs from methanogenic archaea are called noncanonical or atypical or methanogenic-type SerRSs.

\section{Noncanonical Roles of SerRS}

Discoveries of diversified noncanonical cellular roles of the aaRS at first circumvented the SerRS system. SerRS was perceived as a "well behaved", archetypal class II aaRS, without documented additional or moonlighting functions. In 2005 extensive review of SerRSs by Weygand \& Cusack ${ }^{[35]}$ placed emphasis on structural and mechanistic insights of serylation, determinants of tRNA ${ }^{\text {Ser }}$ recognition, complicated and paraphyletic evolution of the seryl-tRNA synthetases. However, recent findings convincingly break the view of SerRSs as the exemplar aaRS dedicated exclusively to the translation of genetic information. First, in several bacterial species duplications of SerRS have been detected, and were shown to be linked to the antibiotic production or resistance. In both cases the telltale observation was that the additional, duplicated SerRS gene was located in the gene 

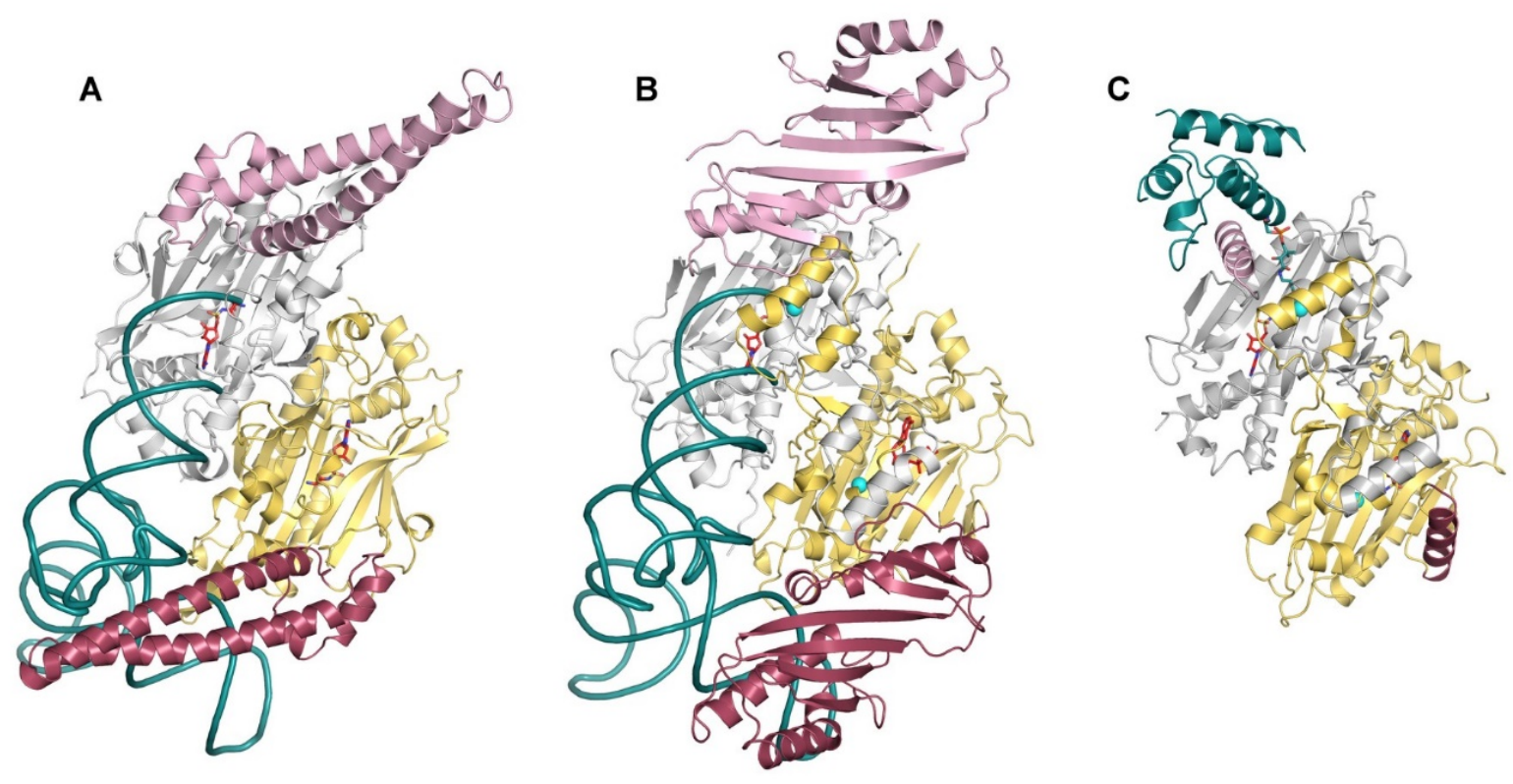

Figure 1. The structure of seryl-tRNA synthetases and homologous amino acid:[carrier protein] ligases.

The model of canonical or bacterial-type SerRS (A) and atypical or methanogenic-type SerRS (B) in complex with tRNA. Bacterialtype SerRS complex with tRNA is modelled according to the published structure of Thermus thermophilus SerRS complex.[26] The model of methanogenic-type SerRS:tRNA ${ }^{\text {Ser }}$ complex is based on M. barkeri SerRS structure ${ }^{[28]}$ on which the tRNA was superposed, based on structural and experimental considerations. Dimeric structure of the enzymes is emphasized by different shades of colors. C-terminal catalytic domains are shown in gray and yellow, and the N-terminal tRNA binding domains are shown in light and dark magenta. The tRNA backbone is shown in teal. The location of the active site is signposted by aminoacyladenylates bound within and shown in sticks.

The structure of Gly:CP ligase from Bradyrhizobium diazoefficiens in complex with cognate $\mathrm{CP}[130]$ is shown in panel C. The CP is shown in teal, and the helix responsible for CP binding is shown in light and dark magenta in respective subunits (gray and yellow). The cyan spheres in panel B and C denote the zinc ions located in the active site of atypical SerRS and Gly:CP ligase.

cluster for antibiotic biosynthesis. Streptomyces sp. strain ATCC 700974 produces albomycin, the siderophore which upon cell entry proteolytically releases a nucleoside moiety conjugated to siderophore in a parent compound albomycin. The released nucleoside is a potent inhibitor of SerRS, so a divergent SerRS resistant to the inhibitor encoded by albomycin biosynthetic cluster protects the producer from self-poisoning . ${ }^{[36]}$ On the other hand, a duplicated SerRS within the valanimycin biosynthesis cluster from Streptomyces viridifaciens apparently provides building blocks for valanimycin synthesis, since it was shown that seryl-tRNAser is one of the valanimycin precursors ${ }^{[37]}$ and SerRS gene inactivation diminishes the antibiotic production. ${ }^{[38]}$ It is noteworthy that in both examples of albomycin and valanimycin biosynthesis, duplicated SerRSs still play their aboriginal role - tRNA ${ }^{\text {Ser }}$ serylation.

However, the SerRS paralogue in Drosophila melanogaster is a different story. Beside the genes for cytosolic and mitochondrial SerRS, a third gene coding for a SerRSlike protein can be found in all available insect genomes. The third SerRS paralogue is the result of mitochondrial
SerRS gene duplication and the protein - called SLIMP (seryl-tRNA synthetase-like insect mitochondrial protein) has no catalytic activity. ${ }^{[39]}$ SLIMP localizes to the mitochondria, and it is essential for the proper mitochondrial function and morphogenesis. SLIMP is an example of an aaRSlike protein that has acquired a new role, similar to the secondary regulatory roles of the metazoan aaRS.

Distinctive feature of the eukaryotic cytosolic SerRSs is a C-terminal extension, known as UNE-S (domain unique to SerRS), not present in the bacterial counterparts. [40] Two independent forward-genetic studies in zebrafish demonstrated involvement of vertebrate SerRS in vascular development. ${ }^{[41,42]}$ Random chemical mutagenesis introduced premature stop-codons within the gene for cytosolic SerRS, leading to abnormal blood vessel formation and defective blood circulation in the zebrafish embryo. The human SerRS also affects angiogenesis, and SerRS influence on vascular development is independent of its catalytic activity. ${ }^{[41]}$ The noncanonical activity was linked to the dysregulation of vascular endothelial growth factor A (VEGFA) expression, a key regulator of angiogenesis and vasculogenesis. ${ }^{[41]}$ 
Subsequent work on human SerRS revealed that UNE-S harbors a strong nuclear localization signal (NLS) directing SerRS to the nucleus where SerRS decreases VEGFA expression, [34] by antagonizing c-Myc, the major transcription factor promoting VEGFA expression. ${ }^{[43]}$ In conclusion, vertebrate SerRS acts as a regulator of gene expression and the noncanonical role of SerRS essential for vascular development depends on UNE-S.

Recent research substantially reshaped our view on seryl-tRNA synthetases, revealing several unexpected noncanonical functions of SerRS and SerRS-like proteins. In this paper we review contribution of Ivana WeygandĐurašević's work to the SerRS field - her lifelong main field of scientific interest. The research of Ivana WeygandĐurašević and coworkers in recent years was focused on fundamental, mechanistic questions of tRNA serylation of both bacterial-type and methanogenic-type SerRS. SerRS does not have an editing domain, but the work on yeast SerRS provided evidence of proofreading activity in the SerRS active (synthetic) site. Another topic of research interest was investigation of the previously unexplored plant SerRSs, leading to their better characterization and analysis of intracellular localization. Further research on atypical SerRS from methanogenic archaea (reviewed in S. Bilokapić et al. (2009) $\left.{ }^{[44]}\right)$ led to the discovery of SerRS interaction with ArgRS and translating ribosomes. The implications of the SerRS interaction with translating machinery is discussed in this review. The presence of homologous shortened genes similar to atypical archaeal SerRS in genomes of many bacterial species drew our attention, resulting in the discovery and characterization of a novel enzyme family called amino acid:[carrier protein] ligases (aa:CP ligases). These SerRS paralogs charge distinctive carrier proteins instead of tRNA with various amino acids, and clearly have abandoned the conventional role of aaRS in ribosomal translation. Structural, biochemical and computational studies provided an in depth analysis of the interaction between the aa:CP ligase and cognate carrier protein, revealing an unanticipated mode of interaction between the enzyme and its macromolecular partner. SerRS and SerRS-like proteins continue to unveil exciting discoveries and still represent an active field of research.

\section{SerRS: A PROOFREADING ENZYME WITHOUT THE ERROR-CORRECTION DOMAIN}

The fidelity of a cognate amino acid recognition is frequently jeopardized by the structurally and chemically similar, non-cognate amino acids that compete for the interaction with the corresponding aaRS. To prevent mistakes in the aminoacyl-tRNA synthesis and a subsequent fall in cellular viability and fitness, the error-prone aaRSs evolved hydrolytic editing reactions (Figure 2) to eliminate the incorrect aminoacyl-adenylate intermediates and/or misaminoacylated tRNAs. ${ }^{[45,46]}$ Post-transfer editing is the key proofreading pathway and it comprises rapid hydrolysis of misacylated tRNA in a separate dedicated protein domain. In addition, pre-transfer editing eliminates a noncognate aminoacyl-AMP intermediate within the synthetic site. This activity can be stimulated by tRNA. Elucidation of the pre-transfer editing mechanism was challenging, partially because of the aminoacyl-adenylates' inherent instability, which precluded their routine use in mechanistic studies. It was initially proposed ${ }^{[47]}$ that both pre- and posttransfer editing reactions reside in the same hydrolytic site at a domain specialized for editing. Yet, our comprehensive work on the mechanism of pre-transfer editing proved the model wrong and demonstrated that pre-transfer editing reactions actually reside within the confines of the synthetic site. ${ }^{[48-52]}$ SerRS was the highly important player in establishing this new pre-transfer editing model. as this

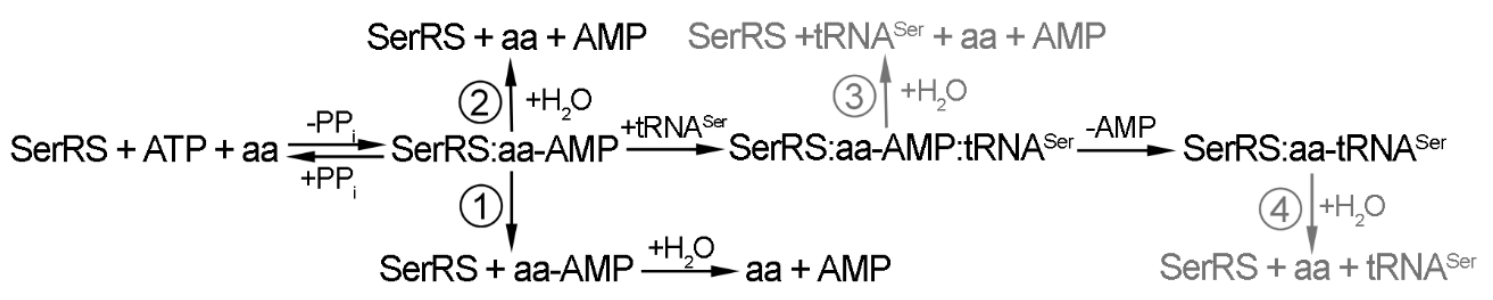

Figure 2: Flowchart of plausible synthetic and proofreading enzymatic activities of seryl-tRNA synthetases.

Synthetic reactions are shown in the middle section of the flowchart and different proofreading reactions are shown above and below. Pre-transfer editing (1-3) can occur through several pathways: enhanced dissociation of the non-cognate aminoacyladenylate (1) or its enzymatic hydrolysis $(2,3)$. These activities may be tRNA-independent $(1,2)$ or tRNA dependent (3). Deacylation of mischarged tRNA is called posttransfer editing (4). Experimentally observed and proven catalytic activities for SerRS are shown in black, and tRNA-dependent proofreading activities $(3,4)$ absent in SerRS are shown in gray. 
enzyme, in all domains of life, naturally lacks a domain specialized in editing. ${ }^{[21,28,34,53,54]}$ In spite of that, it may hydrolyze both non-cognate and non-natural aminoacylAMPs, apparently within the synthetic module. ${ }^{[48,55]}$ Work on the yeast SerRS provided the first strong indication that the pre-transfer editing reactions do not depend on the separate editing module. This contradicted the broadly accepted view in which a proofreading aaRS requires a domain dedicated for proofreading, and opened a completely new perspective on tRNA synthetase editing.

\section{Yeast SerRS Exhibits tRNA-independent Pre-transfer Editing}

SerRS from yeast Saccharomyces cerevisiae can activate non-cognate threonine and cysteine with the efficiency that is close to the tolerated discrimination factor in protein biosynthesis. ${ }^{[48]}$ The discrimination factor is defined as $\left(\left[k_{\text {cat }} / K_{\mathrm{M}}\right.\right.$ (cognate) $] /\left[k_{\text {cat }} / K_{\mathrm{M}}(\right.$ non-cognate $\left.\left.)\right]\right)$ and it expresses the protein's misactivation frequency; the values below $\mathbf{3 3 0 0}$ manifests a misactivation that is more frequent than the measured overall translational mistake. To prevent a potential error in serylation, the enzyme evolved an error-correction step prior the aminoacyl transfer to tRNA (pre-transfer editing). The observed threonine- and cysteine-dependent AMP formation $\left(k_{\text {obs }}=3 \times 10^{-3} \mathrm{~s}^{-1}\right)$ was 10 fold faster than the rate of non-enzymatic hydrolysis of the corresponding aminoacyl-AMPs $\left(0.2 \times 10^{-3} \mathrm{~s}^{-1}\right)$, demonstrating that both threonyl- and cysteinyl-AMP were hydrolyzed within the SerRS synthetic site. Cognate tRNA ${ }^{\text {Ser }}$ did not stimulate aminoacyl-AMP hydrolysis, providing clear evidence that SerRS utilizes only the tRNA-independent pre-transfer editing pathways. The reported weak pretransfer editing may argue against the biological relevance of SerRS proofreading. The rates of transfer of cysteinyl and threonyl moiety to tRNA ${ }^{\text {Ser }}$ were not determined, precluding any direct comparison of the competing reactions within the SerRS synthetic site (aminoacyl transfer to tRNA or to water). Nevertheless, the observed insensitivity of the AMP accumulation rate on the presence of tRNA may suggest that aminoacyl-AMP hydrolysis and the aminoacyl transfer step do not compete significantly. Thus, it is reasonable to assume that to some extent tRNA-independent editing contributes to the fidelity of serylation. This is consistent with our hypothesis ${ }^{[51]}$ in which synthetic site-based pre-transfer editing is primordial, less effective and preferentially tRNA-independent proofreading, which may still be found in some contemporary aaRSs.

Elimination of non-cognate aminoacyl-AMP from the reaction pathway may take place through the enzyme based hydrolysis or via enhanced dissociation of aminoacylAMP followed by its non-enzymatic hydrolysis in solution (often named as the selective release pathway, Figure 2). Yeast SerRS employs both pathways when eliminating threonyl-adenylate. ${ }^{[48]}$ The analogous mechanism was reported for non-cognate alanine elimination by prolyl-tRNA synthetase (ProRS) from humans and Methanococcus jannaschii, ${ }^{[56]}$ and for clearing seryl-AMP by threonyl-tRNA synthetase (ThrRS) from yeast mitochondria. ${ }^{[57]}$ In all cases, the enzyme-catalyzed aminoacyl-AMP hydrolysis was the dominant form of editing, with a "selective release" of noncognate adenylate from the active site constituting a minor pathway. Both ProRS and ThrRS naturally lack editing domains in the aforesaid cases, while they still comprise the separate editing module in majority of organisms. Thus, it appears that SerRS is the only enzyme deprived of the separate editing module in all domains of life which clearly demonstrate the pre-transfer editing activity.

\section{Activated Serine Hydroxymate is Cleared by Pre-transfer Editing}

Work on SerRS further contributed to a novel perception about editing by showing that this activity is not necessarily a consequence of the long-term evolution against natural non-cognate substrates, but may also exist towards the unnatural amino acids or their analogues. This "unexpected" aaRS features may pose a problem for incorporation of unnatural amino acids into proteins. This follows from our finding that the yeast SerRS exhibited the most prominent editing activity with an unnatural serine analogue, serine hydroxamate. ${ }^{[48]}$ This analogue, which has a hydroxamate group instead of carboxylate, inhibits $E$. coli growth ${ }^{[58]}$ primary through the inhibition of $E$. coli SerRS. ${ }^{[59]}$ Besides the E. coli enzyme, it also inhibits yeast SerRS but with somewhat lower inhibitory constant. ${ }^{60,61]}$ We have recently shown that both canonical and atypical SerRSs also differ in sensitivity to serine hydroxamate. ${ }^{[62]}$ The analogue is activated by yeast ${ }^{[61]}$ and atypical SerRS from Methanosarcina barkeri[63] with high misactivation frequencies (discrimination factor was below 100). Yet, no detectable transfer of serine hydroxamate to tRNA ${ }^{\text {Ser }}$ has been observed in case of the yeast enzyme, while a very low activity was measured for the atypical SerRS, [63] explaining the inhibitory effect of the analogue. Surprisingly, serine hydroxamate is eliminated through hydrolysis of its adenylate within the synthetic active site of both canonical[48] and atypical SerRSs. ${ }^{[55]}$ As anticipated, this activity was not stimulated by tRNA.

\section{INSIGHTS INTO FUNCTIONAL AND CELLULAR PROPERTIES OF PLANT SerRSs}

In general, plant aminoacyl-tRNA synthetases are less studied than the aaRSs from other organisms. The distinctive feature of the plant cellular biology is that the protein biosynthesis occurs in three separate cellular compartments. Therefore, the presence of aminoacyl-tRNA synthetases is 
required in chloroplasts, mitochondria and the cytosol, and their subcellular localization is of special interest in plant aaRSs research. Localization studies were mostly directed towards Arabidopsis organellar aaRSs where it was shown that dual localization is the rule and that the organellar aaRSs were either dually localized to mitochondria and chloroplasts or to mitochondria and cytosol. ${ }^{[64,65]}$

\section{Localization in Maize and Arabidopsis Thaliana}

Bioinformatics analysis of the maize genome data identified only two separate SerRS genes encoding two dissimilar SerRS proteins. ${ }^{[66]}$ Thus, one of them should be dually targeted to account for the SerRS function needed in three protein synthesizing compartments. One of the identified maize SerRS proteins is targeted exclusively to maize cytosol[67] (Figure 3), aminoacylates yeast and maize cytosolic tRNAs ${ }^{\text {Ser }}$ and complements the function of the yeast cytosolic SerRS. ${ }^{[68]}$ The other SerRS protein complements the function of the $E$. coli SerRS ${ }^{[69]}$ and aminoacylates efficiently mitochondrial and chloroplasts tRNAs ${ }^{\mathrm{Ser}},{ }^{[70]}$ indicating its organellar function. Using combination of complementary methods, including in vitro import assay into purified organelles, in vivo GFP-tagging and immunodetection we demonstrated that this protein is dually targeted to both maize mitochondria and chloroplasts ${ }^{[71]}$ (Figure 3). This dual localization of organellar SerRS is established by the virtue of the ambiguous targeting peptide at its $\mathrm{N}$-terminus that contains features characteristic of mitochondrial presequences and plastid transit peptides. In chloroplasts, the organellar SerRS was not associated with thylakoids, but was targeted to the plastid stroma, which is the most plausible site for aaRS action in plastids. Moreover, we observed targeting of protein to stromules, the stroma-filled plastid tubules, highly dynamic thin protrusions emanating from the plastid surface. ${ }^{[72]}$ Maize organellar SerRS is the first example of dually targeted monocot aaRS, and one of the very few examples of dually targeted proteins to plastids and mitochondria in maize. ${ }^{[73,74]}$

During our analysis of plant SerRSs we noted that the cytosolic SerRS from Arabidopsis thaliana contains several amino acid sequences that resemble bipartite nuclear localization signals. ${ }^{[75]}$ This observation raised the possibility that, in addition to being present in the cytosol for protein biosynthesis, Arabidopsis SerRS might also be directed to the nucleus, as it was previously shown for the human SerRS. ${ }^{[34,76]}$ However, our thorough immunolocalization and GFP-localization studies in plant protoplasts and transgenic plants revealed exclusive cytosolic localization of $A r-$ abidopsis SerRS. ${ }^{\text {[75] }}$ Considering that localization of the protein can vary in different conditions[77] and that Arabidopsis cytosolic SerRS was implicated in the early response to stress elicited by cadmium exposure, ${ }^{[78]}$ we also
ZmcSerRS-GFP
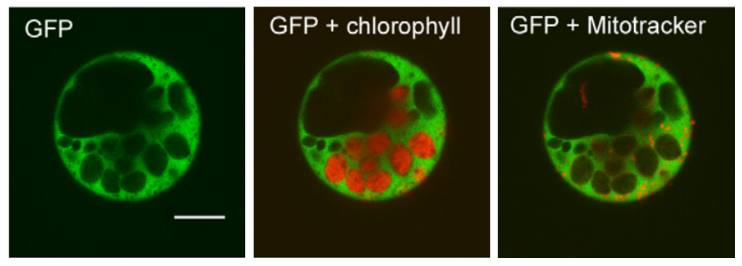

ZmoSerRS-GFP
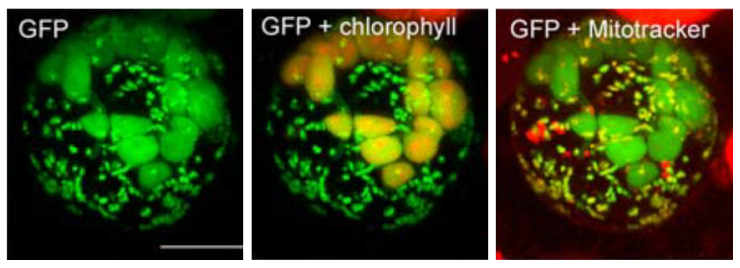

Figure 3: Localization of two maize seryl-tRNA synthetases ZmcSerRS and ZmoSerRS visualized by confocal fluorescent microscopy.

Proteins fused with GFP were transiently expressed in maize protoplasts. Upper panel: ZmcSerRS is localized in cytosol. Lower panel: Dual targeting of organellar ZmoSerRS to chloroplasts and mitochondria. Yellow color represents superposition of green and red indicating colocalization of ZmoSerRS and chloroplasts (middle) and ZmoSerRS and mitochondria (right). GFP, GFP fluorescence, GFP + chlorophyll represents merging of GFP (green) and chlorophyll (red) fluorescent signals. Chlorophyll identifies chloroplasts. GFP + Mitotracker represents merging of GFP (green) and Mitotracker (red) fluorescent signals. Mitotracker is a fluorescent dye specific for mitochondria. Scale bars, $10 \mu \mathrm{m}$.

tested whether Arabidopsis cytosolic SerRS protein can be redirected to nucleus under various stress conditions. Our results with transgenic seedlings expressing GFP-SerRS construct revealed that the abiotic stress conditions do not change cytosolic location of SerRS. ${ }^{\text {[75] }}$

\section{Specific Features of tRNA Recognition and Aminoacylation}

The recognition of tRNA by aaRSs is facilitated by both positive and negative identity elements contained within the tRNA structure that ensure binding to the proper enzyme. ${ }^{\text {[9] }}$ Recognition studies performed with the components of serylation systems from different species revealed that some, but not all, determinants have been conserved during evolution. $[35,44,80,81]$ The main recognition element required for productive SerRS:tRNA ${ }^{\text {Ser }}$ complex formation is the long variable arm of tRNA $A^{\text {Ser }}$, present in all organisms except in animal mitochondria. Length and orientation of the variable arm were shown to be important for proper 
Table 1. Cross-species recognition of tRNA ${ }^{\text {Ser }}$ determined from in vitro (aminoacylation) and in vivo (complementation) assays

\begin{tabular}{|c|c|c|c|c|}
\hline \multirow[t]{2}{*}{ SerRS } & \multicolumn{2}{|c|}{$\begin{array}{l}\text { In vitro (aminoacylation) } \\
\left(k_{\text {cat }} / K_{\mathrm{M}}\right) /\left(\mathrm{s}^{-1} \mu \mathrm{mol}^{-1} \mathrm{dm}^{3}\right)\end{array}$} & \multicolumn{2}{|c|}{ In vivo (complementation) } \\
\hline & Ec tRNA ${ }^{\text {Ser }}$ & Sc tRNA ${ }^{\text {Ser }}$ & EcSerRS & ScSeRS \\
\hline EcSerRS & $4.64^{[135]}$ & n.a. ${ }^{[87]}$ & $++[60]$ & n.d. \\
\hline ScSerRS & $2.5 \times 10^{-4}[60]$ & $1.2^{[60]}$ & $+[60]$ & $++[68]$ \\
\hline MmSerRS & $3.47^{*,[89]}$ & $1.16^{*,[89]}$ & $-[90]$ & $-[136]$ \\
\hline ZmoSerRS & $2.4^{[70]}$ & n.a. ${ }^{[69]}$ & $+[69]$ & n.d. \\
\hline ZmcSerRS & $1.28^{[67]}$ & $1.43^{[68]}$ & $++[67]$ & $++[68]$ \\
\hline
\end{tabular}

EcSerRS, Escherichia coli SerRS; ScSerRS, Saccharomyces cerevisiae SerRS; MmSerRS, Methanococcus maripaludis SerRS; ZmoSerRS, organellar Zea mays SerRS; ZmcSerRS, cytosolic Zea mays SerRS; n.a., no detectable aminoacylation activity; n.d., not determined; *, the values indicate $k_{\mathrm{obs}} / \mathrm{min}^{-1}$; - , no complementation; + , weak complementation; ++, efficient complementation.

recognition of tRNA $A^{\text {Ser }}$ by SerRS enzymes and they differ among three domains of life. ${ }^{[82-85]}$ Cross-species recognition of the tRNA $A^{\text {Ser }}$ determined from in vitro aminoacylation and in vivo complementation assays is shown in Table 1.

As a general rule, efficient recognition of the tRNA by aaRS is dependent on evolutionary origin of both tRNA and aaRS. ${ }^{[86]}$ For example, bacterial SerRS is not able to aminoacylate tRNA ${ }^{\text {Ser }}$ of eukaryotic origin. ${ }^{[70,87]}$ Similarly, the maize organellar SerRS showed clear preference for organellar substrates of endosymbiotic bacterial origin, while no or poor aminoacylation was observed for plant and yeast cytosolic eukaryotic tRNAs ${ }^{\text {Ser }}$. ${ }^{69,70]}$ Yeast cytosolic SerRS can recognize bacterial type tRNA ${ }^{\text {Ser }}$, albeit with a very low efficiency. ${ }^{[88]}$ These observations were explained by the fact that, due to different evolutionary origin, eukaryotic and bacterial tRNAs ${ }^{\text {Ser }}$ have different length and spatial orientation of variable arm. By using in vitro experiments it has been shown that the atypical methanogenic-type archaeal SerRS recognizes tRNAs ${ }^{\text {Ser }}$ from all three domains of life, probably due to the fact that archaeal tRNAs ${ }^{\text {Ser }}$ show mixed bacterial and eukaryotic features. ${ }^{[84,89]}$ However, this SerRS was unable to complement the function of bacterial and yeast SerRSs in vivo. ${ }^{[0]}$

Recently we demonstrated that the maize cytosolic SerRS can efficiently aminoacylate in vitro and in vivo bacterial tRNAs ${ }^{\mathrm{Ser}[67]}$ and eukaryotic cytosolic tRNAs ${ }^{\mathrm{Ser}}{ }^{[67,68]}$ Thus, despite its eukaryotic features and strong similarity to other eukaryotic cytosolic SerRSs, ${ }^{[70]}$ the maize cytosolic SerRS was able to efficiently recognize bacterial tRNAs ${ }^{\text {Ser }}$ that are clearly distinguishable from maize cytosolic tRNAs ${ }^{\text {Ser, }}$ which show typical eukaryotic characteristics, ${ }^{[67,84]}$ Similar broad tRNAs ${ }^{\text {Ser }}$ specificity and flexibility was also shown for Arabidopsis cytosolic SerRS. ${ }^{[75]}$ Broad tRNA ${ }^{\text {Ser }}$ specificity may be related to the evolutionary origin of plant SerRSs. Phylogenetic analysis has shown that the Arabidopsis cytosolic and organellar SerRS genes originated from a duplication event of a gene inherited from Actinobacteria. ${ }^{[91]}$ It is possible that during evolution plant cytosolic SerRS retained efficient recognition of bacterial-type tRNA ${ }^{\text {Ser }}$ species, a functional characteristic that was inherent to the gene product of the bacterial ancestral gene.

\section{Fidelity of Serylation in Plants}

The important aspect of the aaRS activity is the fidelity of the tRNA aminoacylation, from both functional and practical standpoints. Research on the role of aaRSs in maintaining translational accuracy in plants is very limited. This issue is not only important from the functional and evolutionary point of view, but it should also be considered in biotechnology, namely in the recombinant protein production in plant cytosol or chloroplasts. Errors in translation could potentially affect the quality of produced proteins, which is especially relevant in the case of therapeutic recombinant proteins. Proofreading activities were shown for only few plant aaRSs. ${ }^{[92-94]}$ Findings that yeast and archaeal SerRSs showed low or moderate misactivation of near-cognate amino acids and serine analogue SerHX[28,55,95] prompted us to explore the fidelity of the maize cytosolic and dually targeted organellar SerRSs, ${ }^{[67]}$ Organellar SerRS exhibited higher discrimination against threonine, cysteine and SerHX as compared to its cytosolic counterpart. Both enzymes showed pre-transfer editing activity towards tested compounds implying their high overall accuracy. ${ }^{[67]}$ Taking into account that neither of the maize enzymes possesses editing domains, the observed hydrolytic activity towards near-cognate aa-AMPs and SerHX-AMP seems to reside within the synthetic site, as was shown for other SerRSs. ${ }^{[48,55]}$ Our investigation of the maize organellar SerRS is the first and only report on the fidelity of a synthetase serving its role in both mitochondria and plastids. ${ }^{[67]} \mathrm{Re}$ quirements of both plant organelles for translational quality control have not been extensively studied. Two observed fidelity mechanisms of the maize organellar SerRS, high discriminatory power and proofreading, indicate that plant organelles require a high level of translational quality control and that aaRSs in general may play an important role in plant organellar quality control. 


\section{Emerging Noncanonical Roles}

As noted earlier, aaRSs have evolved a wide array of noncanonical functions both inside and outside translation. ${ }^{96,97]}$ Many of those alternative functions arise from interaction of aaRSs with other proteins. ${ }^{[98]}$ There is only one report on alternative function of plant aaRS outside translation. Detection of pathogen-associated molecular patterns during the early stages of pathogen infection in Arabidopsis boosts transcription of the aspartyl-tRNA synthetase gene and triggers translocation of aspartyl-tRNA synthetase from ER to the cytosol where it activates defense mechanisms against pathogen attack. ${ }^{[99]}$ Thus far, protein interactors of plant aaRSs were not identified. Recently, using high throughput interactome technologies we identified a protein involved in the metabolism of brassinosteroid hormones which acts as a protein interactor of Arabidopsis cytosolic SerRS (M. Kekez and J. Rokov-Plavec, in preparation). This interaction indicates a possible noncanonical role of plant SerRS linking hormone metabolism with translation. The exact biological function of the SerRS complex is currently under investigation.

\section{Participation of SerRS in tRNA Recycling and Optimization of Translation}

Association of several aaRSs within multi aminoacyl-tRNA synthetase complexes (MSC) is the key feature of organization of the translation apparatus. In eukaryotes these complexes tend to be larger than those discovered in bacteria and archaea and also perform a wider range of functions that include both aminoacylation and noncanonical roles beyond translation. ${ }^{[17,100,101]}$ Previous studies have suggested a link between the tRNA aminoacylation and highmolecular-weight cellular complexes such as the cytoskeleton or ribosomes. ${ }^{[102-104]}$ In all three domains of life, aaRSs form a variety of complexes with each other and with the non-enzymatic factors, ${ }^{[17,100]}$ which may promote association of aaRSs with the ribosome. ${ }^{[102-104]}$ However, the structural basis of these interactions and potential mechanistic implications are not well understood. Bacterial-type SerRS rarely interacts with other proteins and only a few interacting partners have been identified to date. SerRS was found in a complex with several proteins involved in a DNA replication in TAP-MS proteome-wide screen of Mycoplasma pneumoniae. ${ }^{[105]}$ Our work on the yeast system revealed that S. cerevisiae SerRS predominantly interacts via its characteristic C-terminal extension with peroxin Pex21p, which facilitates tRNA binding and serylation. ${ }^{[106-107]}$

In archaea, macromolecular associations of aaRSs were first described in the extreme halophile Haloarcula marismortui.[108] The tRNA aminoacylation activity of several aaRSs was detected in Thermococcus kodakarensis polysome fractions isolated by sucrose gradients. ${ }^{[104]}$ In Methanothermobacter thermautotrophicus, lysyl-tRNAsynthetase (LysRS) was found to be associated with leucyltRNA-synthetase (LeuRS) and prolyl-tRNA-synthetase (ProRS). ${ }^{[109-111]}$ Besides, LeuRS forms a complex with elongation factor EF-1 alpha ${ }^{[100]}$ adding this interaction to a relatively short list of associations found to be formed between EF-1 alpha and various aaRSs. ${ }^{[109,112]}$

\section{Macromolecular Interactions of Atypical SerRS}

We analyzed protein-protein interactions between the atypical methanogenic-type SerRS from $M$. thermautotrophicus and other components of the archaeal translation machinery by yeast two-hybrid ( $\mathrm{Y} 2 \mathrm{H})$ screen using SerRS as a bait. Using the $\mathrm{Y} 2 \mathrm{H}$ methodology we found that the archaeal SerRS can interact with ribosomal proteins and ArgRS. ${ }^{[113]}$ We found that the key functional outcome of the complex formation between ArgRS and SerRS in archaea is its stimulating effect on the rate of serylation. The optimal activity of SerRS is achieved in a complex with ArgRS at 200-300 mM NaCl and at the temperature of $65^{\circ} \mathrm{C}$ which is in accordance with the growth of $M$. thermautotrophicus under elevated osmolarity and temperature. ${ }^{[114]}$ On the other hand, the archaeal SerRS serylates tRNA ${ }^{\text {Ser }}$ extremely slowly at low ionic strength. The higher concentrations of salt did not abolish the interaction between SerRS and ArgRS, suggesting that the interaction between these two aaRSs is fairly robust. Our data support the notion that SerRS:ArgRS complex may constitute a part of the thermoand osmoadaptation mechanisms of thermophilic methanogenic archaea, by providing an optimal microenvironment for the tRNA aminoacylation under a wide range of conditions. ${ }^{[113]}$

Beside ArgRS, the $\mathrm{Y} 2 \mathrm{H}$ screen identified the ribosomal protein L3 as a SerRS interactor, indicating a possible interaction of the archaeal aaRSs with the ribosome. In further characterization of interactions of archaeal aaRSs with the ribosome we showed by microscale thermophoresis (MST) that atypical SerRS and an archaeal ArgRS bind to the large ribosomal subunit with micromolar affinities.[115] Based on crosslinking data, surface plasmon resonance (SPR) and microscale thermophoresis, three major contact sites were identified between the 50S ribosomal subunit and the investigated aaRSs. The interaction point with the ribosome was narrowed down to several ribosomal proteins that build the P0/P1 stalk and the nearby ribosomal proteins located at the base of the PO/P1 stalk of the 50S subunit. The P0/P1 stalk is a specialized protein-protein interaction platform on the large ribosomal subunit in a proximity to ribosomal A-site, functioning in the recruitment of translation factors EF-1 alpha and EF-G ${ }^{[116]}$ to the ribosome. 
Aminoacyl-tRNAs are inserted into the ribosomal A-site by the activated EF-1 alpha during translation. The interactions of aaRSs with the ribosomal proteins of the P0/P1 stalk could therefore enrich aaRS enzymes in this region, enabling the efficient transfer of their aa-tRNA products to elongation factors and to the translating ribosome. Given the overlapping set of the interaction partners of SerRS and ArgRS on the 50S subunit in the area of P0/P1 stalk (Figure 4A), and the previous observation that SerRS and ArgRS form a complex in M. thermautotrophicus, these two tRNA synthetases could possibly approach the ribosome as a pre-formed complex.

\section{tRNA Channeling Hypothesis}

The hypothesis of tRNA channeling during translation $^{[102,103,117,118]}$ suggests that the synthesis of aa-tRNAs by aaRSs occurs in a close proximity to the translating ribosome (Figure 4A). The interior of the cell is highly crowded with macromolecules, and the tRNAs may not diffuse far after exiting the ribosome. Indeed, they may remain in the vicinity of the ribosome to be recharged and reused for another cycle of elongation. ${ }^{[118]}$ The examination of coding sequences of $M$. thermautotrophicus genome revealed a bias for clustering of synonymous codons (codons that code for the same amino acid). On top of that, a bias to cluster those synonymous codons that are recognized by the same tRNA isoacceptor (i.e., identical codons and isoaccepting codons) was also observed. Once a particular codon has been used, subsequent occurrences of the same amino acid do not use codons randomly, but favor codons that use the same tRNA (Figure 4B). ${ }^{[118]}$ Our bioinformatics analysis of the distribution of the synonymous codons in $M$. thermautotrophicus genome showed a biased serine (Ser) and arginine (Arg) codon ordering in $M$. thermautotrophicus, indicating a possibility of reuse of tRNA ${ }^{\text {Ser }}$ and tRNA Arg on the ribosome. ${ }^{\text {[115] }}$ Therefore, the codon choice may be influenced by the previous upstream codon for the same amino acid; a design that could be favorable for the translation process. ${ }^{[119]}$ This supports a model in which the deacylated tRNAs may be recharged by aaRSs bound to the ribosome and reused at

A
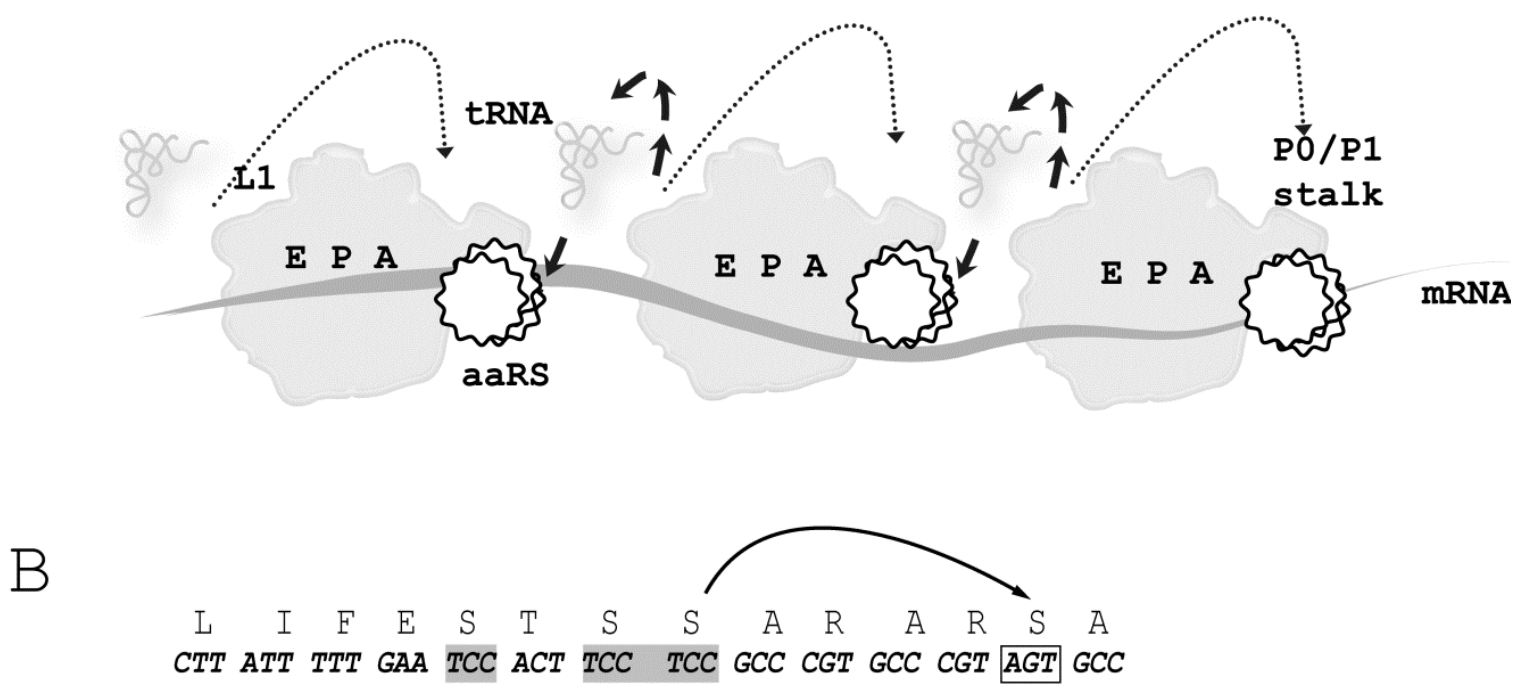

Figure 4: Schematic representation of 50S ribosomal subunit showing the tRNA recycling model and synthetase binding region. (A) Schematic model for tRNA recycling in polysomes. aaRSs (stars) are recruited by the ribosomes in the region of PO/P1 stalk. In polysomes, recycling of tRNAs exiting from the E-site of one ribosome to the next ribosome in the polysome (black lines) may be favored over recycling to the same ribosome (dashed line). (B)

(B) Example of isoacceptor codon autocorrelation. The following example illustrates a part of a hypothetical protein sequence with possible codons marked below. Amino acid serine occurs four times in this sequence and is translated by $\operatorname{tRNA}^{\mathrm{Ser}}{ }_{\mathrm{GGA}}$ Or tRNA ${ }^{\text {Ser }}{ }_{G C T}$ taking into account the classical wobble hypothesis. Serine codons recognized by isoacceptor tRNA ${ }^{\text {Ser }}{ }_{G G A}$ are shown in gray, while serine codon recognized by tRNA ${ }^{S e r}{ }_{G C T}$ is boxed. For the decoding of first three serine codons in this example, it is not required to change the isoacceptor tRNA by the ribosome. For the decoding of the fourth serine codon (boxed), isoacceptor tRNA has to be changed for the decoding process (arrow). Since the number of required tRNA changes by the ribosome quantifies autocorrelation, autocorrelation of serine codons in this example is considered strong because only one tRNA change is required for decoding serine along this string of amino acids. 
the next occurrence of an isoaccepting codon (Figure 4A). Based on that hypothesis we proposed a tRNA recycling model in which the archaeal SerRS and ArgRS associate with P0/P1 stalk region of the ribosome to recapture the tRNAs released from the preceding ribosome in the polysomes. ${ }^{[115]}$ It is noteworthy that multiple ribosomes simultaneously engaged in translation become spaced along single mRNA molecules in polysomes. Under these conditions, the juxtaposition of the L1-stalk/E-site side of one ribosome to the P0/P1 stalk/A-site side of the following ribosome on the mRNA may enable the recycling of a tRNA exiting from one ribosome to translation factors and aaRSs bound at the PO/P1 stalk of the next ribosome. Tomographic reconstructions of bacterial and eukaryotic polysomes in situ suggest that such an arrangement is possible. ${ }^{[120,121]}$

\section{AMINO ACID:[CARRIER PROTEIN] LIGASES: THE HOMOLOGUES OF ATYPICAL ARCHAEAL SerRS CHARGING THE CARRIER PROTEINS}

With the advent of microbial genome sequencing projects, it became apparent that the homologues of the atypical SerRS from methanogenic archaea can be found in many bacteria. Although the sequence similarity between atypical SerRS and their bacterial homologues is rather low (15 $21 \%$ ) and well in "the twilight zone", a thorough sequence analysis has shown that the aaRS class II signature motifs are detectable and conserved ${ }^{[122]}$ in these newly discovered hypothetical proteins. The residues necessary for the zinc binding within the active site of atypical archaeal SerRS are strictly conserved in their bacterial homologues. These SerRS homologues are truncated in comparison to the known atypical archaeal SerRS, and they lack the tRNA binding domain. Hence, the sequence similarity is limited to the catalytic domain of the atypical SerRS. The bacteria hosting the genes encoding these unusual truncated SerRS homologues harbored the genes for conventional fulllength SerRS as well, so we hypothesized that the truncated SerRS homologues of atypical archaeal SerRS might serve a novel role, possibly unrelated to ribosomal protein biosynthesis. ${ }^{[122]}$ In some organisms, like Bradyrhizobium diazoefficiens (previously known as B. japonicum), two separate genes for truncated SerRS homologues can be found.

\section{Amino Acid Activation by SerRS Homologues}

Preliminary biochemical characterization of three representative SerRS homologues, two from Bradyrhizobium diazoefficiens and one from Agrobacterium fabrum (renamed from Agrobacterium tumefaciens) confirmed overall similarity to the atypical archaeal SerRS: the homologues were homodimeric proteins and they possessed two zinc ions per dimer. But only the $A$. fabrum enzyme was capable of serine activation, while both $B$. diazoefficiens enzymes appeared inactive in the active site titration assay with serine. The paradox was resolved when a panel of amino acids was tested as substrates in the ATP - pyrophosphate exchange assay: the $B$. diazoefficiens enzymes were fully active when glycine was offered as a substrate, while the preferred substrate for the A. fabrum homologue was alanine, although the enzyme was also capable of serine and glycine activation to a lesser extent. ${ }^{[122]}$ The switch in amino acid specificity was unexpected, because this feature is usually strictly preserved in the aaRS family. The amino acid specificity of aaRSs was established early in their evolutionary history, in most cases in the dawn of life and before the split of three domains of life, and remained fixed for billions of years. ${ }^{[123]}$ This holds true even for other truncated aaRS homologues dedicated to physiological roles unrelated to the tRNA aminoacylation, such as MshC, CysRS homologue involved in mycothiol biosynthesis in actinomyceta[124] or YadB, GluRS homologue catalyzing tRNA ${ }^{\text {Asp }}$ posttranscriptional hypermodification. ${ }^{[125]}$ The only known exemption is PoxA, the homolog of LysRS recruited to elongator factor $P$ posttranslational modification, using ( $R$ )- $\beta$-lysine instead of proteinogenic lysine, i.e. (S)- $\alpha$-lysine. ${ }^{[126]}$

The crystal structure of the $B$. diazoefficiens homologue (Figure $1 C$ ) showed that the structure of the homologue is remarkably similar to the atypical $M$. barkeri SerRS, although they share a weak sequence similarity ( $15 \%$ identity). ${ }^{[122]}$ The structure of $B$. diazoefficiens homologue recapitulates the structure of $M$. barkeri SerRS catalytic domain, with very few differences within and close to the active site. Atypical SerRS possesses an idiosyncratic region called "serine ordering loop",[28] which is very flexible: it is unstructured in free enzyme, undergoes a profound induced-fit conformational change upon serine binding and, based on the structural considerations and experimental evidence, ${ }^{[30,80]}$ it apparently undergoes further rearrangements and repositioning when the tRNA binds and tRNA acceptor end enters the active site. Curiously, the corresponding region in the crystal structure of the $B$. diazoefficiens homologue exhibits a different conformation, it is located further away from the active site and does not participate in the amino acid binding. The structures of the $B$. diazoefficiens homologue in a complex with the small molecular weight substrates (AMP, ATP, Gly-AMP analogue) provided a detailed picture of glycine activation, the first step of aminoacylation reaction. ATP binds to the active site in the bent conformation, in a manner unique to the class II aaRS. ${ }^{[122,127]}$ The bent conformation of ATP positions the $\alpha$-phosphate for an in-line nucleophilic attack of carboxylate 
group of the amino acid and displacement of pyrophosphate as the leaving group. The analogue of Gly-AMP (5'-O-(N-glycyl-sulfamoyl)adenosine) binds into the active site of $B$. diazoefficiens enzyme in the same way the SerAMP analogue binds to M. barkeri SerRS active site, and in both cases the amino group of aminoacyl- moiety is bound by a zinc ion. However, the Arg353 residue that helps to orient the serine hydroxyl-group in $M$. barkeri SerRS is replaced by Met174 in the B. diazoefficiens homologue, providing the structural rationale for the shift of amino acid specificity of SerRS homologues toward small aliphatic amino acids Gly and Ala. ${ }^{[122]}$ Molecular dynamics (MD) simulations [127] further advanced our understanding of amino acid specificity of the bacterial SerRS homologues and especially the difference between selectivity of the $B$. diazoefficiens and $A$. fabrum homologues. MD simulations have clearly shown that serine can bind the zinc ion within the active site, but it cannot be properly accommodated and oriented to perform nucleophilic attack of the carboxylate group to the $\alpha$-P atom of ATP. The $B$. diazoefficiens enzyme preferentially activates glycine, whereas $A$. fabrum is less stringent in the amino acid recognition: it preferentially activates alanine, but to a lesser extent glycine and serine as well. MD simulations pinpointed residue A281 in the $B$. diazoefficiens enzyme (equivalent to G296 in A. fabrum enzyme) as the major determinant of the differences in selectivity between the two enzymes. Based on the results of in silico analysis, A281G mutant of $B$. diazoefficiens enzyme was designed, and indeed its amino acid selectivity was altered as predicted: the $B$. diazoefficiens A281G mutant efficiently catalyzed alanine activation, much better than glycine, without impairment of its catalytic activity. ${ }^{[127]}$ This is one of the rare examples of a successful tailoring of enzyme amino acid specificity, without significantly crippling its overall catalytic activity.

\section{The Second Step: Transfer of Activated Aminoacyl Moiety to a Protein Acceptor}

The next question was where do the activated amino acids end up and what is their final acceptor? Due to the lack of a tRNA binding domain, it was not expected that tRNA would act as an amino acid acceptor for this class of enzymes, at least not to any appreciable extent. In spite of thorough testing and different tRNA used as the substrate, no tRNA charging activity could be demonstrated. ${ }^{[128]}$ Serendipitously, genomic context of the atypical SerRS homologues pointed to the candidate for the amino acid acceptor. ${ }^{[122]}$ The genes for the SerRS homologues in bacteria are usually accompanied by the genes for the small carrier proteins (CPs), predicted to carry 4'-phosphopantetheinyl- prosthetic group. Such small proteins $(80-100$ amino acids; $\mathrm{Mr} \approx 10000$ ) with a characteristic structure of $4 \alpha$-helix bundle carry activated (amino)acyl residues on their prosthetic group in diverse metabolic pathways: fatty acid synthesis, nonribosomal peptide and polyketide synthesis, synthesis of membrane derived oligosaccharides, signal molecules, cell wall components, etc. ${ }^{[129]}$ In vitro characterization proved that CPs are excellent substrates for the SerRS homologues. ${ }^{[122]}$ Therefore, the shortened bacterial homologues of the atypical SerRS from methanogenic archaea were renamed amino acid:[carrier protein] ligases (AMP forming), abbreviated aa:CP ligases.

Subsequent biochemical analysis has shown many interesting details regarding CP aminoacylation. MS analysis and chemical fluorescent labelling unequivocally showed that sulfhydryl group of the 4'-phosphopantotheine (Ppant) prosthetic arm is the site of amino acid attachment. ${ }^{[122]}$ Kinetic analysis revealed that aa:CP ligases specifically recognize and charge cognate $\mathrm{CPs}$, whose genes are found close to the ligase genes, and will not charge the acyl- CPs devoted to fatty acid synthesis (FAS ACPs). Not surprisingly, aa:CP ligases were capable of aminoacylation of other thiols, such as coenzyme A, dithiothreitol, cysteine, etc., but not as efficient as cognate CPs. ${ }^{[128]}$ The fact that aa:CP ligases do not charge FAS ACPs, lead us to speculate that protein:protein interactions between the $\mathrm{CP}$ and the enzyme are predominant for $\mathrm{CP}$ binding, and that Ppant arm does not contribute significantly to the binding. However, apoCP (CP without the Ppant prosthetic group) did not form a stable complex with the homologue, as evidenced by pull-down and kinetic assays, nor the complex formation could be detected by isothermal titration calorimetry. ${ }^{[130]}$ Furthermore, the apoCP did not act as a competitive inhibitor in a kinetic assay. These experimental observations were corroborated by the in silico study, which confirmed that apo- and holoCP bind with significantly different affinities despite having the same conformation, leading to the conclusion that Ppant arm is required for high affinity binding of $C P$. ${ }^{[131]}$

The crystal structure of $B$. diazoefficiens Gly: $\mathrm{CP}$ ligase in a complex with the cognate $\mathrm{CP}$ was solved ${ }^{[130]}$ and disclosed true surprises. The CP binds to Gly:CP ligase in an unanticipated manner, completely unrelated to the mode of tRNA binding to class II aaRS. The Ppant prosthetic group enters the active site from a completely different direction, compared to the tRNA acceptor end and class II aaRS (Figure 1C), through a tunnel not present in $M$. barkeri SerRS. Furthermore, the opening used by the prosthetic group to access the active site of Gly:CP ligase would be covered by the N-terminal tRNA-binding domain in M. barkeri SerRS. ${ }^{[130]}$ Conversely, the opening used by the tRNA acceptor end in class II aaRS to approach the active site is constricted in $B$. diazoefficiens Gly: $\mathrm{CP}$ ligase. The interaction between the carrier protein and the aa:CP ligase relies solely on the interaction with distinctive helix within the region corresponding to "serine ordering loop" in the atypical 
SerRS. Therefore, the aa:CP ligase helix which mediates the interaction with the $\mathrm{CP}$ is called "CP-binding" or "CPrecognition helix". The analogous region in atypical SerRS has a completely different structure and function, as already described. The CP-recognition helix of the ligase interacts extensively with CP helices II and III. The CP helices II and III form a cleft and grasp around the CP-recognition helix. ${ }^{[130]}$ The complex of $\mathrm{CP}$ and ligase was solved in the presence of small substrates and the reaction intermediates (AMP, ATP, Gly + ATP, Gly-AMP analogue) as well.[130] Together with previous crystallographic work, ${ }^{[122]}$ these structures provided the snapshots of the whole catalytic cycle and allowed us to propose a possible catalytic mechanism of CP aminoacylation. The first step of amino acid activation proceeds through a conventional in-line displacement mechanism by nucleophilic attack of the glycine carboxylate group to $\alpha$-phosphate of ATP, ${ }^{[122]}$ as already mentioned. In the second step, transfer of activated amino acid to sulfhydryl group of Ppant arm advances through nucleophilic attack of the Ppant sulfhydryl group on the glycyladenylate carbonyl leading to the thioester bond formation. We have proposed that the thioester bond formation proceeds through a substrate-assisted concerted mechanism without direct participation of the protein residues acting as the general base during amino acid transfer. Rather, the active site residues guide the reaction through transition state by properly orienting the substrates, additional polarization and stabilization of the reacting groups. ${ }^{[130]}$

Curiously, the sequence conservation of the $\mathrm{CP}$ recognition helix is rather low, and the analysis of $\mathrm{CP}$ and aa:CP ligase phylogeny reveals higher evolutionary divergence of CPs and aa:CP ligases from $B$. diazoefficiens and $A$. fabrum Ala:CP ligase than anticipated. ${ }^{[130]}$ As the consequence, heterologous aminoacylation of the CPs by the enzyme from the different organism is quite inefficient in the case of $B$. diazoefficiens and $A$. fabrum. Since the interaction between the ligase and the cognate $\mathrm{CP}$ is dependent exclusively on the CP-binding helix, we have replaced the $\mathrm{CP}$-binding helix in $B$. diazoefficiens $\mathrm{Gly}: \mathrm{CP}$ ligase with the counterpart from the $A$. fabrum Ala:CP ligase. ${ }^{[130]}$ The chimeric enzyme turned out to be fully active, and effectively charged heterologous $A$. fabrum CP with glycine, whereas cognate $B$. diazoefficiens $\mathrm{CP}$ was charged with appreciably lower affinity. The complete reversal of specificity toward CPs was achieved with replacement of only 11 residues, demonstrating once again that recognition between the two proteins relies exclusively on the CP-recognition helix.

\section{A Link With Nonribosomal Peptide Synthesis}

The physiological role of aa:CP ligases and the fate of activated amino acids bound to distinctive CPs is currently unknown. It is tempting to speculate that aa:CP ligase may be involved in a nonribosomal peptide synthesis - a widespread method of non-templated secondary metabolite production, ${ }^{[132]}$ due to the mechanistic similarity of aa:CP ligases with adenylation domains, which funnel amino acids into this biosynthetic machinery. Adenylation domains like aaRSs catalyze the two-step reaction of peptidyl carrier protein aminoacylation, with enzyme-bound aminoacyl-adenylate as the intermediate. ${ }^{[133]}$ However, adenylation domains are members of the so-called ANL superfamily (together with firefly luciferase and acyl-CoA synthetases) and structurally and evolutionary are unrelated to the class I and II aaRS. Engagement of aa:CP ligases in nonribosomal peptide synthesis would be a long-sought link between the two fundamentally different systems for peptide synthesis, and it would be an interesting example of the evolutionary crosstalk or module exchange between ribosomal and nonribosomal peptide synthesis. ${ }^{[122,134]}$ Some authors speculate that discovery of aa:CP ligases supports the "thioester world" hypothesis, ${ }^{[134]}$ in which a thioester chemistry of nonribosomal peptide synthesis preceded the "RNA world", emergence of nucleic acids and the template-directed ribosomal protein synthesis. Whatever the fate of acylated CPS turns out to be, it is clear that activated amino acids are diverted from ribosomal translation and that aa:CP ligases adapted to sustain a novel, yet unknown, biosynthetic pathway.

\section{CONCLUSION AND OUTLOOK}

After decades of research, the SerRS is nowadays well characterized representative of aminoacyl-tRNA synthetases. The structural data is abundant and spans all three domains of life, including peculiar and divergent SerRSs like the mammalian mitochondrial and the atypical archaeal SerRSs. Although SerRS kept its basic two-domain organization during the evolution (comprising $\mathrm{N}$-terminal tRNAbinding domain and C-terminal catalytic domain), it was remarkably amenable to evolutionary invention: additional extensions appeared to complement its function in the mammalian mitochondrial translation or to recruit it as an angiogenesis regulatory factor in vertebrates. Atypical SerRSs and their truncated bacterial homologues - aa:CP ligases continue to intrigue. Interaction of atypical SerRS with the ribosome and other components of translational machinery may be functionally important and lead to optimized and more efficient translation. This possibility neatly extends the tRNA channeling hypothesis. Direct experimental evidence would be valuable, but it is difficult to obtain in methanogenic archaea. The biological function of aa:CP ligases is currently unknown, and it is the subject of our scientific interest.

Research on the fidelity and proofreading of aaRS intensified in recent years and re-emerged as a hot topic in 
the aaRS field due to the rising appreciation that proofreading activity may protect the proteome from incorporation and infiltration of non-proteinogenic and/or unnatural amino acids. The fact that SerRS possesses pre-transfer editing activity raises the question of its biological significance, so our future research will focus on the editing activity in mammalian systems and its role in protection against a challenge with non-proteinogenic amino acids. Plant aaRSs are not extensively studied compared to the aaRS from other kingdoms of life. Our comprehensive research of the plant SerRSs contributed to their better characterization in terms of their localization, tRNA recognition and fidelity. In addition, the organellar SerRS emerged as a new important player in the plant organellar protein quality control. Future research of the plant cytosolic SerRS will be directed towards elucidation of the new noncanonical function discovered by our group.

In conclusion, the research of the seryl-tRNA synthetases in our and other laboratories has proven that even the old players in the aaRS field can perform new tricks, and we are eager to decipher the secrets and untold abilities they may be hiding from us.

Acknowledgment. We would like to express sincere gratitude to our supervisor Ivana Weygand-Đurašević who inspired us for years on the scientific journey on the SerRS pathway. We thank dr. Morana Dulić for providing Figure 2 and dr. Iva Kavčić for carefully reading the manuscript. This work was supported by a grant from Croatian Science Foundation (09.01/293) and the European Community's Seventh Framework Programme (FP7RegPot/ IntegraLife, 315997).

\section{REFERENCES}

[1] F. H. Crick, Symp. Soc. Exp. Biol. 1958, 12, 138.

[2] P. C. Zamecnik, E. B. Keller, J. Biol. Chem. 1954, 209, 337.

[3] M. B. Hoagland, E. B. Keller, P. C. Zamecnik, J. Biol. Chem. 1956, 218, 345.

[4] E. W. Davie, V. V. Koningsberger, F. Lipmann, Arch. Biochem. Biophys. 1956, 65, 21.

[5] M. B. Hoagland, P. C. Zamecnik, M. L. Stephenson, Biochem. Biophys. Acta 1957, 24, 215.

[6] M. B. Hoagland, M. L. Stephenson, J. F. Scott, L. I. Hecht, P. C. Zamecnik, J. Biol. Chem. 1958, 231, 241.

[7] M. Ibba, D. Söll, Annu. Rev. Biochem. 2000, 69, 617.

[8] R. Mukhopadhyay, J. Jia, A. Arif, P. S. Ray, P. L. Fox, Trends Biochem. Sci. 2009, 34, 324.

[9] Y. Ofir-Birin, P. Fang, S. P. Bennett, H. -M. Zhang, J. Wang, I. Rachmin, R. Shapiro, J. Song, A. Dagan, J. Pozo, S. Kim, A. G. Marshall, P. Schimmel, X. -L. Yang, H. Nechushtan, E. Razin, M. Guo, Mol. Cell 2013, 49, 30.

[10] X. -L. Yang, P. Schimmel, K. L. Ewalt, Trends Biochem. Sci. 2004, 29, 250.
[11] M. Guo, X. -L. Yang, Top. Curr. Chem. 2014, 344, 89.

[12] M. Frugier, M. Ryckelynck, R. Giegé, EMBO Rep 2005, 6, 860.

[13] H. Moine, P. Romby, M. Springer, M. GrunbergManago, J. -P. Ebel, B. Ehresmann, C. Ehresmann, J. Mol. Biol. 1990, 216, 299.

[14] G. Mohr, R. Rennard, A. D. Cherniack, J. Stryker, A. M. Lambowitz, J. Mol. Biol. 2001, 307, 75.

[15] M. Frechin, B. Senger, M. Brayé, D. Kern, R. P. Martin, H. D. Becker, Genes Dev. 2009, 23, 1119.

[16] M. Frechin, D. Kern, R. P. Martin, H. D. Becker, B. Senger, FEBS Lett. 2010, 584, 427.

[17] S. Havrylenko, M. Mirande, Int. J. Mol. Sci. 2015, 16, 6571.

[18] M. Guo, X. -L. Yang, P. Schimmel, Nat. Rev. Mol. Cell Biol. 2010, 11, 668.

[19] H. Schwenzer, J. Zoll, C. Florentz, M. Sissler, Top. Curr. Chem. 2014, 344, 247.

[20] R. C. Wallen, A. Antonellis, Curr. Opin. Genet. Dev. 2013, 23, 302.

[21] S. Cusack, C. Berthet-Colominas, M. Härtlein, N. Nassar, R. Leberman, Nature 1990, 347, 249.

[22] G. Eriani, M. Delarue, O. Poch, J. Gangloff, D. Moras, Nature 1990, 347, 203.

[23] S. Cusack, Nat. Struct. Biol. 1995, 2, 824.

[24] H. Belrhali, A. Yaremchuk, M. Tukalo, K. Larsen, C. Berthet-Colominas, R. Leberman, B. Beijer, B. Sproat, J. Als-Nielsen, G. Grübel, J. -F. Legrand, M. Lehmann, Stephen Cusack, Science 1994, 263, 1432.

[25] V. Biou, A. Yaremchuk, M. Tukalo, S. Cusack, Science 1664, 263, 1404.

[26] S. Cusack, A. Yaremchuk, M. Tukalo, EMBO J. 1996, 15, 2834.

[27] S. Chimnaronk, M. G. Jeppesen, T. Suzuki, J. Nyborg, K. Watanabe, EMBO J. 2005, 24, 3369.

[28] S. Bilokapić, T. Maier, D Ahel, I. Gruić-Sovulj, D. Söll, I. Weygand-Đurašević, N. Ban, EMBO J. 2006, 25, 2498.

[29] S. Bilokapić, N. Ivić, V. Godinić-Mikulčić, I. Piantanida, N. Ban, I. Weygand-Đurašević, J. Biol. Chem. 2009, 284, 10706.

[30] M. Dulić, J. Požar, S. Bilokapić, I. Weygand-Đurašević, Ita Gruić-Sovulj, Biochimie 2011, 93, 1761.

[31] Y. Itoh, S. Sekine, C. Kuroishi, T. Terada, M. Shirouzu, S. Kuramitsu, S. Yokoyama, RNA Biol. 2008, 5, 169.

[32] R. Rocha, P. J. B. Pereira, M. A. S. Santos, S. MacedoRibeiro, Proc. Natl. Acad. Sci. U. S. A. 2011, 108, 14091.

[33] E. T. Larson, E. A. Merritt, Medical Structural Genomics of Pathogenic Protozoa, 10.2210/pdb3lsq/pdb; 10.2210/pdb3lss/pdb

[34] X. Xu, Y. Shi, H. -M. Zhang, E. C. Swindell, A. G. Marshall, M. Guo, S. Kishi, X. -L. Yang, Nat. Commun. 2012, 3, 681. 
[35] I. Weygand-Đurašević, S. Cusack, Seryl-tRNA Synthetases in The Aminoacyl-tRNA Synthetases (Eds.: M. Ibba, C. Francklyn, S. Cusack), Landes Biosciences, Georgetown (SAD), 2005., pp. 177-192.

[36] Y. Zeng, H. Roy, P. B. Patil, M. Ibba, S. Chen, Antimicrob. Agents Chemother. 2009, 53, 4619.

[37] R. P. Garg, X. L. Qian, L. B. Alemany, S. Moran, R. J. Parry, Proc. Natl. Acad. Sci. U. S. A. 2008, 105, 6543.

[38] R. P. Garg, Y. Ma, J. C. Hoyt, R. J. Parry, Mol. Microbiol. 2002, 46, 505.

[39] T. Guitart, T. L. Bernardo, J. Sagalés, T. Stratmann, J. Bernués, L. Ribas de Pouplana, J. Biol. Chem. 2010, 285, 38157.

[40] I. Weygand-Đurašević, B. Lenhard, S. Filipić, D. Söll, J. Biol. Chem. 1996, 271, 2455.

[41] H. Fukui, R. Hanaoka, A. Kawahara, Circ. Res. 2009, 104, 1253.

[42] W. Herzog, K. Müller, J. Huisken, D. Y. Stainier, Circ. Res. 2009, 104, 1260.

[43] Y. Shi, X. Xu, Q. Zhang, G. Fu, Z. Mo, G. S. Wang, S. Kishi, X. -L. Yang, elife 2014, 3, e02349.

[44] S. Bilokapić, N. Ban, I. Weygand-Đurašević, Croat. Chem. Acta 2009, 82, 493.

[45] H. Jakubowski, Wiley Interdiscip. Rev. RNA 2012, 3, 295.

[46] J. J. Perona, I. Gruić-Sovulj, Top. Curr. Chem. 2014, $344,1$.

[47] A. C. Bishop, T. K. Nomanbhoy, P. Schimmel, Proc. Natl. Acad. Sci. U. S. A. 2002, 99, 585.

[48] I. Gruić-Sovulj, J. Rokov-Plavec, I. WeygandĐurašević, FEBS Lett. 2007, 581, 5110.

[49] M. Dulić, N. Cvetešić, J. J. Perona, I. Gruić-Sovulj, J. Biol. Chem. 2010, 285, 23799.

[50] N. Cvetešić, J. J. Perona, I. Gruić-Sovulj, J. Biol. Chem. 2012, 287, 25381.

[51] M. Dulić, J. J. Perona, I. Gruić-Sovulj, Biochemistry 2014, 53, 6189.

[52] N. Cvetešić, A. Palencia, I. Halasz, S. Cusack, I. GruićSovulj, EMBO J. 2014, 33, 1639.

[53] M. Fujinaga, C. Berthet-Colominas, A. D. Yaremchuk, M. A. Tukalo, S. Cusack, J. Mol. Biol. 1993, 234, 222.

[54] B. Lenhard, S. Filipić, I. Landeka, I. Škrtić, D. Söll, I. Weygand-Đurašević, J. Biol. Chem. 1997, 272, 1136.

[55] I. Gruić-Sovulj, M. Dulić, I. Weygand-Đurašević, Croat. Chem. Acta 2011, 84, 179.

[56] K. E. Splan, M. E. Ignatov, K. Musier-Forsyth, J. Biol. Chem. 2008, 283, 7128.

[57] J. Ling, K. M. Peterson, I. Simonović, D. Söll, M. Simonović, J. Biol. Chem. 2012, 287, 28518.

[58] T. Tosa, L. I. Pizer, J. Bacteriol. 1971, 106, 966.

[59] T. Tosa, L. I. Pizer, J. Bacteriol. 1971, 106, 972.

[60] I. Weygand-Đurašević, N. Ban, D. Jahn, D. Söll, Eur. J. Biochem. 1993, 214, 869.
[61] I. Landeka, S. Filipić-Rocak, B. Žinić, I. WeygandĐurašević, Biochim. Biophys. Acta 2000, 1480, 160.

[62] D. Ahel, D. Slade, M. Močibob, D. Söll, I. WeygandĐurašević, FEBS Lett. 2005, 579, 4344.

[63] I. Gruić-Sovulj, M. Dulić, J. Jarić, N. Cvetešić, K. Majsec, I. Weygand-Đurašević, Croat. Chem. Acta 2010, 83, 163.

[64] A. M. Duchêne, A. Giritch, B. Hoffmann, V. Cognat, D. Lancelin, N. M. Peters, M. Zaepfel, L. MarechalDrouard, I. D. Small ID, Proc. Natl. Acad. Sci. U. S. A. 2005, 102, 16484.

[65] A. M. Duchêne, C. Pujol, L. Maréchal-Drouard, Curr. Genet. 2009, 55, 1.

[66] J. Rokov, I. Weygand-Đurašević, Period. Biol. 1999, 101, 137.

[67] J. Rokov-Plavec, S. Lesjak, I. Gruić-Sovulj, M. Močibob, M. Dulić, I. Weygand-Đurašević, Arch. Biochem. Biophys. 2013, 129, 122.

[68] M. Močibob, I. Weygand-Đurašević, Arch. Biochem. Biophys. 2008, 470, 129.

[69] J. Rokov, D. Söll, I. Weygand-Đurašević, Plant Mol. Biol. 1998, 38, 497.

[70] J. Rokov-Plavec, S. Lesjak, I. Landeka, I. Mijaković, I. Weygand-Đurašević, Arch. Biochem. Biophys. 2002, 397, 40.

[71] J. Rokov-Plavec, M. Dulić, A. M. Duchêne, I. Weygand-Đurašević, Plant Cell Rep. 2008, 27, 1157.

[72] K. Delfosse, M. R. Wozny, E. A. Jaipargas, K. A. Barton, C. Anderson, J. Mathur, Front. Plant Sci. 2016, 6, 1253.

[73] T. A. Beardslee, S. Roy-Chowdhury, P. Jaiswal, L. Buhot, S. Lerbs-Mache, D. B. Stern, L. A. Allison, Plant J 2002, 31, 199.

[74] A. Bahaji, M. Ovecka, I. Bárány, M. C. Risueño, F. J. Muñoz, E. Baroja-Fernández, M. Montero, J. Li, M. Hidalgo, M. T. Sesma, I. Ezquer, P. S. Testillano, J. Pozueta-Romero, Plant Cell Physiol. 2011, 52, 597.

[75] M. Kekez, E. Šarić, N. Bauer, J. Rokov-Plavec, J. Plant Biol 2016, 59, 44.

[76] Y. Shi, X. Xu, Q. Zhang, G. Fu, Z. Mo, G. S. Wang, S. Kishi, X. L Yang, eLife 2014, 3, e02349

[77] N. Wei, Y. Shi, L. N. Truong, K. M. Fisch, T. Xu, E. Gardiner, G. Fu, Y. S. Hsu, S. Kishi, A. I. Su, X. Wu, X. L. Yang, Mol. Cell 2014, 56, 323.

[78] J. E. Sarry, L. Kuhn, C. Ducruix, A. Lafaye, C. Junot, V. Hugovieux, A. Jourdain, O. Bastien, J. B. Fievet, D. Valihen, B. Amekraz, C. Moulin, E. Ezan, J. Garin, J. Bourguignon, Proteomics 2006, 6, 2180.

[79] R. Giegé, M. Sissler, C. Florentz, Nucleic Acids Res. 1998, 26, 5017.

[80] S. Bilokapić, J. Rokov Plavec, N. Ban, I. WeygandĐurašević, FEBS J. 2008, 275, 2831.

[81] I. Gruić-Sovulj, J. Jarić, M. Dulić, M. Cindrić, I. Weygand-Đurašević, J. Mol. Biol. 2006, 361, 128. 
[82] H. Asahara, H. Himeno, K. Tamura, N. Nameki, T. Hasegawa, M. Shimizu, J. Mol. Biol. 1994, 236, 738.

[83] D. Korenčić, C. Polycarpo, I. Weygand-Đurašević, D. Söll, J. Biol. Chem. 2004, 279, 48780.

[84] J. Rokov-Plavec, S. Bilokapić, I. Gruić-Sovulj, M. Močibob, F. Glavan, M. Brgles, I. WeygandĐurašević, Period. Biol. 2004, 106, 147.

[85] X. Q. Wu, H. J. Gross, Nucleic Acids Res. 1993, 21, 5589.

[86] A. Steinmetz, J. H. Weil, Methods Enzymol. 1986, 118, 212.

[87] A. Soma, H. Himeno, Nucleic Acids Res. 1998, 6, 4374.

[88] I. Weygand-Đurašević, N. Ban, D. Jahn, D. Söll, Eur. J. Biochem. 1993, 214, 869.

[89] S. Bilokapić, D. Korenčić, D. Söll, I. WeygandĐurašević, Eur. J. Biochem. 2004, 271, 694.

[90] S. Lesjak, I. Weygand-Đurašević, FEMS Microbiol. Lett. 2009, 294, 111.

[91] M. M. Brãndao, M. C. Silva-Filho, Mol. Biol. Evol. 2011, 28, 79.

[92] R. Rauhut, H. J. Gabius, F. Cramer, Biochemistry 1985, 24, 4052.

[93] H. Jakubowski, Biochemistry 1980, 19, 5071.

[94] H. Jakubowski, A. Guranowski, J. Biol. Chem. 2003, 278,6765 .

[95] I. Gruić-Sovulj, J. Rokov-Plavec, I. WeygandĐurašević, FEBS Lett. 2007, 581, 5110.

[96] M. Guo, P. Schimmel, Nat. Chem. Biol. 2013, 9, 145.

[97] T. J. Bullwinkle, M. Ibba, Top. Curr. Chem. 2014, 344, 43.

[98] J. H. Kim, J. M. Han, Kim S, Top. Curr. Chem. 2014, 344, 119.

[99] E. Luna, M. van Hulten, Y. Zhang, O. Berkowitz, A. López, P. Pétriacq, M. A. Sellwood, B. Chen, M. Burrell, A. van de Meene, C. M. Pieterse, V. Flors, J. Ton, Nat. Chem. Biol. 2014, 10, 450.

[100] C. D. Hausmann, M. Ibba, FEMS Microbiol Rev. 2008, 32, 705.

[101] P. S. Ray, A. Arif, P. L. Fox, Trends Biochem Sci. 2007, 32, 158.

[102] M. Kaminska, S. Havrylenko, P. Decottignies, P. Le Maréchal, B. Negrutskii, M. Mirande, J. Biol. Chem. 2009, 284, 13746.

[103] A. David, N. Netzer, M. B. Strader, S. R. Das, C. Y. Chen, J. Gibbs, P. Pierre, J. R. Bennink, J. W. Yewdell, J. Biol. Chem. 2011, 286, 20688.

[104] M. Raina, S. Elgamal, T. J. Santangelo, M. Ibba, FEBS Lett. 2012, 586, 2232.

[105] S. Kühner, V. van Noort, M. J. Betts, A. Leo-Macias, C. Batisse, M. Rode, T. Yamada, T. Maier, S. Bader, P. Beltran-Alvarez, D. Castaño-Diez, W. H. Chen, D. Devos, M. Güell, T. Norambuena, I. Racke, V. Rybin,
A. Schmidt, E. Yus, R. Aebersold, R. Herrmann, B. Böttcher, A. S. Frangakis, R. B. Russell, L. Serrano, P. Bork, A. C. Gavin, Science. 2009, 326, 1235.

[106] S. Ročak, I. Landeka, I. Weygand-Đurašević, FEMS Microbiol Lett. 2002, 214, 101.

[107] V. Godinić, M. Močibob, S. Ročak, M. Ibba, I. Weygand-Đurašević, FEBS J. 2007, 274, 2788.

[108] Y. Goldgur, M. Safro, Biochem. Mol. Biol. Int. 1994, 32, 1075.

[109] C. D. Hausmann, M. Praetorius-Ibba, M. Ibba, Nucleic Acids Res. 2007, 35, 6094.

[110] M. Praetorius-lbba, T. E. Rogers, R. Samson, Z. Kelman, M. Ibba, J. Biol. Chem. 2005, 280, 26099.

[111] M. Praetorius-Ibba, C. D. Hausmann, M. Paras, T. E. Rogers, M. Ibba, J. Biol. Chem. 2007, 282, 3680.

[112] G. Bec, P. Kerjan, J. P. Waller, J. Biol. Chem. 1994, 269, 2086.

[113] V. Godinić-Mikulčić, J. Jarić, C. D. Hausmann, M. Ibba, I. Weygand-Đurašević, J. Biol. Chem. 2011, 286, 3396.

[114] D. D. Martin, R. A. Ciulla, M. F. Roberts, Appl. Environ. Microbiol. 1999, 65, 1815.

[115] V. Godinić-Mikulčić, J. Jarić, B. J. Greber, V. Franke, V. Hodnik, G. Anderluh, N. Ban, I. WeygandĐurašević, Nucleic Acids Res. 2014, 42, 5191.

[116] M. Diaconu, U. Kothe, F. Schlünzen, N. Fischer, J. M. Harms, A. G. Tonevitsky, H. Stark, M. V. Rodnina, M. C. Wahl, Cell 2005, 121, 991.

[117] M. Mirande, FEBS Lett. 2010, 584, 443.

[118] G. Cannarozzi, N. N. Schraudolph, M. Faty, P. von Rohr, M. T. Friberg, A. C. Roth, P. Gonnet, G. Gonnet, Y. Barral, Cell 2010, 141, 355.

[119] T. E. Quax, N. J. Claassens, D. Söll, J. van der Oost, Mol Cell. 2015, 59, 149.

[120] F. Brandt, S. A. Etchells, J. O. Ortiz, A. H. Elcock, F. U. Hartl, W. Baumeister, Cell 2009, 136, 261.

[121] F. Brandt, L. A. Carlson, F. U. Hartl, W. Baumeister, K. Grünewald, Mol. Cell 2010, 39, 560.

[122] M. Močibob, N. Ivić, S. Bilokapić, T. Maier, M. Luić, N. Ban, I. Weygand-Đurašević, Proc. Natl. Acad. Sci. U. S. A. 2010, 107, 14585.

[123] P. O'Donoghue, Z. Luthey-Schulten, Microbiol. Mol. Biol. Rev. 2003, 67, 550.

[124] D. Sareen, M. Steffek, G. L. Newton, R. C. Fahey, Biochemistry 2002, 41, 6885.

[125] M. Blaise, H. D. Becker, J. Lapointe, C. Cambillau, R. Giegé, D. Kern, Biochimie 2005, 87, 847.

[126] H. Roy, S. B. Zou, T. J. Bullwinkle, B. S. Wolfe, M. S. Gilreath, C. J. Forsyth, W. W. Navarre, M. Ibba, Nat. Chem. Biol. 2011, 7, 667.

[127] A. Maršavelski, S. Lesjak, M. Močibob, I. WeygandĐurašević, S. Tomić, Mol. BioSyst. 2014, 10, 3207.

[128] M. Močibob, N. Ivić, D. Šubašić, M. Luić, Ivana Weygand-Đurašević, Croat. Chem. Acta 2011, 84, 149. 
[129] A. C. Mercer, M. D. Burkart, Nat. Prod. Rep. 2007, 24, 750.

[130] M. Močibob, N. Ivić, M. Luić, I. Weygand-Đurašević, Structure 2013, 21, 614.

[131] A. Maršavelski, M. Močibob, I. Gruić-Sovulj, Robert Vianello, Phys. Chem. Chem. Phys. 2015, 17, 19030.

[132] R. Finking, M. A. Marahiel, Annu. Rev. Microbiol. 2004, 58, 453.
[133] A. M. Gulick, ACS Chem. Biol. 2009, 4, 811.

[134] H. Jakubowski, FEBS Lett. 2016, 590, 469.

[135] F Borel, C Vincent, R Leberman, M Härtlein, Nucleic Acids Res. 1994, 22, 2963.

[136] S. Lesjak, Suppression of bacterial amber mutations by the archaeal tRNASer/seryl-tRNA synthetase pair, doctoral thesis, University of Zagreb, Zagreb 2011. 